LINGUA, Vol. 16, No. 1, Maret 2019

p ISSN: 1979 9411; e ISSN: 2442 238X

Http://lingua.pusatbahasa.or.id; Email:presslingua@gmail.com

Center of Language and Cultural Studies, Surakarta, Indonesia

Anwar, Khairil; Syahdan \& Fadjri, Muhammad. 2019. Ameliorasi Bahasa Sasak pada Masyarakat Tutur di Desa Sengkerang, Praya Timur: Kajian Sosiolinguistik. Lingua (2019), 16(1): 121 136. DOI: 10.30957/lingua.v16i1.580.

\title{
AMELIORASI BAHASA SASAK PADA MASYARAKAT TUTUR DI DESA SENGKERANG, PRAYA TIMUR: KAJIAN SOSIOLINGUISTIK
}

\author{
Khairil Anwar, Syahdan \& Muhammad Fadjri \\ Magister Pendidikan Bahasa Indonesia Universitas Mataram \\ Jalan Majapahit No. 6 Mataram Nusa Tenggara Barat \\ Corresponding Email: anwarkhairil273@gmail.com
}

\begin{abstract}
This study attempts to see amelioration form and its meaning Sasak language spoken in Sengkerang village and explores the reasons for using in a speech community. This study employed a qualitative descriptive method. Data were collected using observation and interview. Records using audio visual aids were used to administer the observation and interview. Prior to analysis, records were transcribed verbatim to see their categories and classifications. Data were analyzed using theories proposed by Allan Keith and Keith Burridge, the steps of which included: reduction, data presentation and conclusion. Results show that there are eleven forms of amelioration in Sengkerang village, namely 1) figurative, 2) flippancy, 3) remodeling, 4) circumcision, 5) clipping, 6) acronym, 7) abbreviation, 8) jargon, 9) hypernym, 10) hyponym, and 11) hyperbole. Meaning of the amelioration form is attached which it is spoken based on the context of which the speech is produced by a speaker. In addition, factors affecting to use the amelioration include: humanity, physiological, characteristic, religiosity, and humor.
\end{abstract}

Keywords: Amelioration, forms, meaning, and factors.

DOI: $10.30957 /$ lingua.v16i1.580.

\section{PENDAHULUAN}

Bahasa dan budaya dalam masyarakat bagaikan dua sisi mata uang yang tidak dapat dipisahkan. Hal itu disebabkan karena bahasa dan budaya memiliki suatu ikatan dan keterkaitan. Bahasa merupakan sebuah perwujudan dari suatu kebudayaan. Semakin baik bahasa yang digunakan oleh suatu masyarakat maka semakin baik pula kebudayaan yang dimiliki oleh masyarakat tersebut.

Kata-kata yang sering dilarang untuk diucapkan bisa terjadi karena kata tersebut dianggap tabu untuk langsung diucapkan. Misalkan seperti yang terjadi di desa Sengkerang kecamatan Praya Timur. Masyarakat di desa Sengkerang ketika hendak menyebut orang (biasanya perempuan) yang tidak sholat dikarenakan hait tidak langsung menyebut hait melainkan diganti dengan frase "dateng temoe". Hal tersebut juga berlaku di dalam bahasa Indonesia. Di dalam bahasa Indonesia kata hait sering diganti dengan ucapan datang bulan. 
LINGUA, Vol. 16, No. 1, Maret 2019

p ISSN: 1979 9411; e ISSN: 2442 238X

Http://lingua.pusatbahasa.or.id; Email:presslingua@gmail.com

Center of Language and Cultural Studies, Surakarta, Indonesia

Anwar, Khairil; Syahdan \& Fadjri, Muhammad. 2019. Ameliorasi Bahasa Sasak pada Masyarakat Tutur di Desa Sengkerang, Praya Timur: Kajian Sosiolinguistik.

Lingua (2019), 16(1): 121 136. DOI: 10.30957/lingua.v16i1.580.

Bahasa yang memiliki nilai rasa lebih tinggi di dalam masyarakat seperti kata ope yang berarti sering lupa karena usia yang sudah sangat tuadiganti dengan kata uzur yang bermakna lebih halus. Oleh karena itu, penelititertarik untuk mengkaji "Ameliorasi Bahasa Sasak Pada Masyarakat Tutur di desa Sengkerang Kec. Praya Timur:Kajian Sosiolinguistik". Peneliti merasa masyarakat tutur di desa Sengkerang sering menggunakan kata-kata atau kalimat yang nilai rasanya lebih tinggi dengan maksud dan tujuan tertentu.

Berangkat dari perihal di atas maka dapat ditarik rumusan masalah yaitu bagaimanakah bentuk dan makna penggunaan ameliorasi bahasa Sasak pada masyarakat tutur di desa Sengkerang Kec. Praya Timur.

Adapun teori yang dijadikan piranti untuk mengetahui bentuk dan makna ameliorasi bahasa Sasak pada masyarakat tutur di desa Sengkerang Kec. Praya Timur antara lain, Teori Ameliorasi Allan dan Burridge. Pemahaman mengenai penghalusan makna ini juga dijelaskan oleh dua orang tokoh barat yaitu Allan dan Burridge di dalam bukunya yang berjudul Euphemism \& Dysphemism Language Used as Shield and Weapon.Allan dan Burridge menyebut istilah ameliorasi dengan istilah Euphemism, sehingga di dalam penelitian ini yang akan dijadikan landasan teori untuk mengkaji penggunaan ameliorasi di desa Sengkerang kecamatan Praya Timur menggunakan teori Allan dan Burridge.

Allan dan Burridge (dalam Zulkifli, 2014:27) mengklasifikasikan ameliorasi ke dalam enam belas bentuk. Adapun bentuk-bentuk ameliorasi menurut Allan dan Burridge adalah sebagai berikut. 1) Ekspresi Figuratif (Figurative Espression), yaitu bersifat perlambangan, ibarat atau kiasan sesuatu dengan bentuk lain. Artinya, bentuk ameliorasi yang menyimpang dari referennya, 2) Metafora (Methafor), yaitu perbandingan yang implisit di antara dua hal yang berbeda, 3) Flipansi (Flippancy), yaitu menghaluskan suatu kata, tetapi makna kata yang dihasilkan di luar pernyataan, 4) Memodelkan Kembali (Remodeling), yaitu pembentuk ulang, 5) Sirkumlokusi (Cirkumlocutions), yaitu penghalusan suatu kata dengan menggunakan beberapa kata yang lebih panjang dan bersifat tidak langsung, 6) Kliping (Clipping), yaitu pemotongan, membuat menjadi pendek atau singkat, 7) Akronim (Accronym), yaitu penyingkatan atas beberapa kata menjadi satu, 8) Singkatan (Abbreviations), yaitu singkatan kata-kata menjadi beberapa huruf, 9) Pelesapan (Omission), yaitu menghilangkan sebagian kecil, 10) Satu kata untuk menggantikan satu kata yang lain (one for one substitutions), 11) Hipernim (general for spesific), yaitu kata yang umum menjadi kata yang khusus, 12) Hiponim (part for whole euphemisms), yaitu kata yang khusus menjadi kata yang umum, 13) Hiperbola (Hyperbole), yaitu ungkapan yang melebih-lebihkan, 14) Makna di luar pernyataan (understatement), yaitu satu makna kata yang terlepas dari makna kata tersebut, 15) Jargon, yaitu kata yang memiliki makna yang sama tetapi berbeda bentuk, 16) Kolokial (Colloquial), yaitu ungkapan yang dipakai sehari-hari.

Selain berbicara mengenai bentuk ameliorasi di atas, Allan dan Burridge juga menyinggung makna ameliorasi. Adapun makna ameliorasi yang dikemukakan oleh Allan dan Burridge berhubungan dengan makna atau tujuan sebuah tuturan. Tuturan yang diujarkan oleh seseorang (penutur) tidak semata-mata mengatakan sesuatu dengan 
LINGUA, Vol. 16, No. 1, Maret 2019

p ISSN: 1979 9411; e ISSN: 2442 238X

Http://lingua.pusatbahasa.or.id; Email: presslingua@gmail.com

Center of Language and Cultural Studies, Surakarta, Indonesia

Anwar, Khairil; Syahdan \& Fadjri, Muhammad. 2019. Ameliorasi Bahasa Sasak

pada Masyarakat Tutur di Desa Sengkerang, Praya Timur: Kajian Sosiolinguistik.

Lingua (2019), 16(1): 121 136. DOI: 10.30957/lingua.v16i1.580.

mengucapkan tuturan itu, namun penutur juga menginginkan sesuatu. Oleh karena itu makna suatu ucapan tergantung pada pemakaiannya.

Pateda (2001:193) menyebutkan beberapa faktor penyebab terjadi upaya penghalusan makna (ameliorasi), yaitu: (i) pertimbangan psikologis, maksudnya agar orang tidak tersinggung perasaannya, orang tidak merasa tertekan secara psikologis; (ii) pertimbangan secara politis, maksudnya agar masyarakat tidak sampai terganggu ketenteramannya, mengganggu keamanan; (iii) pertimbangan sosiologis, maksudnya agar masyarakat tidak resah; (iv) pertimbangan religius, maksudnya agar orang yang dikenai kata tidak akan tertekan imannya; dan (v) pertimbangan kemanusiaan, manusia mempunyai hak yang disebut hak-hak asasi manusia, yang antara lain menyangkut martabat dan kehormatan pribadi, dan bahwa manusia yang satu dengan yang lain memiliki hak yang sama.

Dalam kaitannya dengan perubahan makna kata atau pun pergeseran makna yang digunakan oleh masyarakat tutur seiring dengan perkembangan manusia dan budaya saat ini, tentu beragam sikap pula dari masyarakat dalam menyikapi perubahan atau pergeseran makna tersebut. Khusus kaitannya dengan makna ameliorasi, yang berarti peninggian makna dengan maksud menghaluskan kata agar terasa lebih bernilai dan dengan maksud supaya masyarakat menyikapi pergeseran itu dengan positif.

\section{METODE}

Subjek penelitian ini adalah penutur bahasa Sasak yang ada di desa Sengkerang kecamatan Praya Timur. Sedangkan, data yang dicari dalam penelitian ini berwujud tuturan. Data tuturan ini dalam bentuk pemakaian makna ameliorasi. Sumber data ini diperoleh dari penutur bahasa Sasak yang ada di desa Sengkerang. Penutur yang dijadikan sumber data adalah yang memiliki usia, kelas sosial, budaya, serta jenis kelamin yang berbeda. Pemilihan penutur didasarkan pada tujuan penelitian.

Adapun prosedur pengumpulan data yang akan dilakukan dalam penelitian ini antara lain: (1) Mengobservasi atau menyimak pertuturan yang ada di masyarakat tutur di desa Sengkerang kecamatan Praya Timur, (2) Mencermati komponen-komponen linguistik dalam pertuturan yang dijadikan sumber data berupa kata, frase, klausa, ataupun kalimat yang mengidentifikasikan termasuk dalam katagori ameliorasi, (3) Memberi kode (coding) pada data yang telah dicermati berkaitan dengan penggunaan ameliorasi, makna ameliorasi, faktor penyebab ameliorasi, dan sikap bahasa masyarakat terhadap penggunaan ameliorasi, (4) Menvalidasi data melalui orang yang dianggap ahli dalam bidangnya, dan (5) Memasukkan data yang telah diberi kode ke dalam tiga tabel yaitu wujud penggunaan ameliorasi, makna ameliorasi, dan faktor penggunaan ameliorasi bahasa Sasak di desa Sengkerang kecamtan Praya Timur.

Berikutnya adalah metode analisis data, merupakan tahapan penelitian yang mengkaji untuk mengklasifikasikan dan mengelompokkan data. Pengklasifikasian data harus didasarkan sesuai dengan tujuan penelitian yang akan dipecahkan. Data yang akan dianalisis pada penelitian ini berupa data kualitatif. Metode data yang akan dianalisis dengan cara penganalisisan kualitatif atau deskriptif kualitatif. Deskriptif rujukan data yang menjadi bahan analisis adalah data-data ujaran lisan yang dikumpulkan dari masyarakat saat berinteraksi atau berkomunikasi dengan anggota masyarakat lainnya. 
LINGUA, Vol. 16, No. 1, Maret 2019

p ISSN: 1979 9411; e ISSN: 2442 238X

Http://lingua.pusatbahasa.or.id; Email: presslingua@gmail.com

Center of Language and Cultural Studies, Surakarta, Indonesia

Anwar, Khairil; Syahdan \& Fadjri, Muhammad. 2019. Ameliorasi Bahasa Sasak pada Masyarakat Tutur di Desa Sengkerang, Praya Timur: Kajian Sosiolinguistik.

Lingua (2019), 16(1): 121 136. DOI: 10.30957/lingua.v16i1.580.

Sedangkan, kualitatif merupakan memahami fenomena sosial tentang apa yang dialami oleh subjek penelitian misalnya perilaku, persepsi, motivasi, tindakan, dll., dan dengan cara deskripsi dalam bentuk kata-kata dan bahasa, pada suatu konteks khusus yang alamiah dan dengan memanfaatkan berbagai metode alamiah. Mahsun (2007:257) menjelaskan bahwa kualitatifberarti memahami fenomena sosial kebahasaan yang tengah diteliti.

\section{HASIL DAN PEMBAHASAN}

\subsection{Temuan Ameliorasi Bahasa Sasak di Desa Sengkerang}

Berdasarkan penelitian yang telah dilakukan secara intensif di desa Sengkerang, ditemukan sejumlah data ameliorasi bahasa Sasak yang masih hidup dan berkembang di tengah masyarakat. Keseluruhan temuan ameliorasi yang ditemukan berjumlah 63 (enam puluh tiga). Temuan ameliorasi bahasa Sasak yang ditemukan disajikan dalam bentuk tabel yang memuat transkripsi ortografis, transkripsi fonemik, glosarium dan kode tiap-tiap data ameliorasi (a.1-a.63) supaya lebih jelas penyajiannya dan pembaca mudah dalam memahaminya. Temuan ameliorasi tersebut bisa dilihat pada tabel di bawah ini.

Tabel 1. Temuan ameliorasi bahasa Sasak

\begin{tabular}{|c|c|c|c|c|}
\hline No. & $\begin{array}{l}\text { Ameliorasi Bahasa } \\
\text { Sasak }\end{array}$ & $\begin{array}{l}\text { Peyorasi Bahasa } \\
\text { Sasak }\end{array}$ & Glos & Kode \\
\hline 1. & Kurang penyerioq & Rundam & Kurang penglihatan & a.1 \\
\hline 2. & Ninggal & Mate & Mati & a.2 \\
\hline 3. & Amaq molah & Maling & Maling & a.3 \\
\hline 4. & Kadaq hajat & $\mathrm{Nai}$ & Berak & a.4 \\
\hline 5. & Jauq percek & Selaq & Leak & a.5 \\
\hline 6. & Ajaq & Lekak & Bohong & a.6 \\
\hline 7. & Jual empaq basaq & Ubek & Pelacur & a.7 \\
\hline 8. & Penyakit berat & Berong & Kusta & a.8 \\
\hline 9. & Sundes & Sundel & Sundel & a.9 \\
\hline 10. & Base & Basong & Anjing & a.10 \\
\hline 11. & Pelolat & Sogoq & Sogok & a.11 \\
\hline 12. & Anak bukal & Anak maling & Anak maling & a.12 \\
\hline 13. & Macel & Lejah & Bengel & a.13 \\
\hline 14. & Lolat & Nakal & Curang & a.14 \\
\hline 15. & Belo & Lenjang & $\begin{array}{l}\text { Badan yang sangat } \\
\text { tinggi }\end{array}$ & a.15 \\
\hline
\end{tabular}


LINGUA, Vol. 16, No. 1, Maret 2019

p ISSN: 1979 9411; e ISSN: 2442 238X

Http://lingua.pusatbahasa.or.id; Email: presslingua@gmail.com

Center of Language and Cultural Studies, Surakarta, Indonesia Anwar, Khairil; Syahdan \& Fadjri, Muhammad. 2019. Ameliorasi Bahasa Sasak pada Masyarakat Tutur di Desa Sengkerang, Praya Timur: Kajian Sosiolinguistik. Lingua (2019), 16(1): 121 136. DOI: 10.30957/lingua.v16i1.580.

\begin{tabular}{|c|c|c|c|c|}
\hline 16. & $J b$ & Jaber beweh & $\begin{array}{l}\text { Bibir bagian bawah } \\
\text { yang besar }\end{array}$ & a. 16 \\
\hline 17. & Ganteng & Galang tengaq & Botak & a. 17 \\
\hline 18. & Sri maseh & Solong & Botak & a. 18 \\
\hline 19. & Kurang perengah & Gedok & Tuli & a.19 \\
\hline 20. & Kepeng pelolat & Kepeng sogoan & Uang sogoan & a. 20 \\
\hline 21. & Empet & Pepeq & Vagina & a. 21 \\
\hline 22. & Koboq & Susu & Payu dara & a. 22 \\
\hline 23. & Linggis & Telor & Kemaluan & a. 23 \\
\hline 24. & Tunggang & Ancot & Berhubungan intim & a. 24 \\
\hline 25. & Tolang nangke & Tolang telor & Buah zakar & a. 25 \\
\hline 26. & Termos & Terune mosot & Bujang lapuk & a. 26 \\
\hline 27. & Bunga & Bucung ngangaq & $\begin{array}{l}\text { Bentuk bibir yang } \\
\text { mancung }\end{array}$ & a. 27 \\
\hline 28. & Toldo & Tolang doang & Kurus & a. 28 \\
\hline 29. & Mokoh & Gendut & Gendut & a. 29 \\
\hline 30. & $K s p$ & Kalah siq pepeq & Kalah oleh perempuan & a.30 \\
\hline 31. & Anak kurang bulan & Anakjadah & Anak haram & a.31 \\
\hline 32. & Jadek & Jadah & Anak haram & a.32 \\
\hline 33. & Godes & Godek & Monyet & a.33 \\
\hline 34. & Tainine & Tele nine & Vagina perempuan & a.34 \\
\hline 35. & Tolang telenines & Tolang telen inaq & $\begin{array}{ll}\text { Tulang } & \text { kelentit } \\
\text { perempuan } & \\
\end{array}$ & a.35 \\
\hline 36. & Ojok aiq & Mele Nai/meneq & Mau berak/kencing & a.36 \\
\hline 37. & Bejowong & Kepineng & Pusing & a.37 \\
\hline 38. & Dateng temoe & Het & Hait & a.38 \\
\hline 39. & Kongon & Engkah terengah & Tidak didengar lagi & a.39 \\
\hline 40. & Kenterap timus & & Iri hati & a. 40 \\
\hline 41. & Manjaq & Kodeq susu & Payudara kecil & a. 41 \\
\hline 42. & Robek lending semen & Ndek perawan & Tidak perawan & a. 42 \\
\hline 43. & Bukan beleq otak & Maleng buaq & Pencuri buah & a.43 \\
\hline 44. & Eson kapok & Rambok & Uban & a.44 \\
\hline
\end{tabular}


LINGUA, Vol. 16, No. 1, Maret 2019

p ISSN: 1979 9411; e ISSN: 2442 238X

Http://lingua.pusatbahasa.or.id; Email: presslingua@gmail.com

Center of Language and Cultural Studies, Surakarta, Indonesia

Anwar, Khairil; Syahdan \& Fadjri, Muhammad. 2019. Ameliorasi Bahasa Sasak pada Masyarakat Tutur di Desa Sengkerang, Praya Timur: Kajian Sosiolinguistik.

Lingua (2019), 16(1): 121 136. DOI: 10.30957/lingua.v16i1.580.

\begin{tabular}{|c|c|c|c|c|}
\hline 45. & Pep & Pepeq & Vagina & a. 45 \\
\hline 46. & beraiq erung & Seleme & Pilek & a.46 \\
\hline 47. & pereq beweh & guam & sariawan & a.47 \\
\hline 48. & peres mate & ngantok & ngantuk & a. 48 \\
\hline 49. & panas tian & lapah & lapar & a.49 \\
\hline 50 & leteng tian & sakit tian & sakit perut & a. 50 \\
\hline 51. & maraq datu & girang besuruq & seperti datu & a. 51 \\
\hline 52. & maraq anak datu & $\begin{array}{l}\text { girang suruq dengan } \\
\text { saq lebih toaq }\end{array}$ & seperti anak datu & a. 52 \\
\hline 53. & maraq raje & girang besuruq & seperti raja & a. 53 \\
\hline 54. & maraq anak raje & $\begin{array}{l}\text { girang suruq dengan } \\
\text { saq lebih toaq }\end{array}$ & seperti anak raja & a.54 \\
\hline 55. & maraq bos & lueq kepeng & seperti bos & a. 55 \\
\hline 56. & maraq anak bos & lueq kemeleq & seperti anak bos & a.56 \\
\hline 57. & maraq jongos & girang tesuruq & seperti anak buah & a.57 \\
\hline 58. & kapong jengku & susah & susah & a.58 \\
\hline 59. & tindoq bareng & ngancot & bersenggama & a.59 \\
\hline 60. & wahng ntaq leq surge & Mate & meninggal & a. 60 \\
\hline 61. & wahng ntaq ngipi & pirem & sudah tidur & a.61 \\
\hline 62. & $\begin{array}{l}\text { wahng ntaq dateng } \\
\text { mekah embok }\end{array}$ & pirem & sudah tidur & a. 62 \\
\hline 63 & But & jabut & $\begin{array}{l}\text { bulu di bagian tubuh } \\
\text { yang lebat }\end{array}$ & a.63 \\
\hline
\end{tabular}

\subsection{Klasifikasi Ameliorasi Berdasarkan Bentuk dan Makna}

Mengacu pada rumusan masalah yang ada pada penelitian ini, ameliorasi bahasa Sasak yang ditemukan di desa Sengkerang dapat diklasifikasikan menjadi sebelas kategori bentuk yaitu; 1) bentuk figuratif; 2) flipansi; 3) memodelkan kembali; 4) sirkumlokusi; 5) kliping; 6) akronim; 7) singkatan; 8) jargon; 9) hipernim; 10) hiponim;dan 11) hiperbola. Kesebelas bentuk ameliorasi tersebut berdasarkan enam belas bentuk ameliorasi yang dikemukakan oleh Allan Keith dan Keith Burridge. Untuk lebih jelasnya, berikut akan diuraikan satu persatu bentuk dan makna ameliorasi bahasa Sasak tersebut berdasarkan klasifikasi masing-masing.

\section{Bentuk Figuratif (Figurative Espression)}

Bentuk Figuratif (Figurative Expression) yaitu bersifat perlambangan, ibarat atau kiasan sesuatu dengan bentuk lain. Artinya, bentuk ameliorasi yang menyimpang 
LINGUA, Vol. 16, No. 1, Maret 2019

p ISSN: 1979 9411; e ISSN: 2442 238X

Http://lingua.pusatbahasa.or.id; Email:presslingua@gmail.com

Center of Language and Cultural Studies, Surakarta, Indonesia

Anwar, Khairil; Syahdan \& Fadjri, Muhammad. 2019. Ameliorasi Bahasa Sasak

pada Masyarakat Tutur di Desa Sengkerang, Praya Timur: Kajian Sosiolinguistik.

Lingua (2019), 16(1): 121 136. DOI: 10.30957/lingua.v16i1.580.

dari referennya. Bentuk ini sering digunakan oleh masyarakat di desa Sengkerang ketika berkomunikasi. Bentuk ini digunakan bertujuan untuk menyamarkan maksud sesungguhnya. Masyarakat tutur di desa Sengkerang menggunakan kata-kata yang bersifat perlambangan untuk mengekspresikan perasaannya terhadap sesuatu yang dirasakannya. Bentuk figuratif yang berhasil ditemukan di dalam penelitian ini yaitu (a.51) maraq datu // sepertidatu //, (a.52) maraq anak datu //seperti anak datu//,(a.53) maraq raje //seperti raja //,(a.54) maraq anak raje//seperti anak raja//,(a.55) maraq bos// seperti bos //, (a.56) maraq anak bos //seperti anak bos//. Berikut akan dijelaskan satu persatu makna dari bentuk figuratif yang ditemukan dalam penelitian ini.

\section{(a.51) maraq datu // seperti datu//}

Farasamaraqdatu// seperti datu// termasuk ke dalam kategori bentuk figuratif karena merupakan perlambangan dari orang yang suka menyuruh. Orang yang suka menyuruh akan dianggap seperti datu. Kata datu sendiri berarti pimpinan pada satu wilayah hukum atau wilayah kedatuan. Pada zaman dahulu, di pulau Lombok banyak berdiri kedatuan dan kedatuan itu dipimpin oleh seorang datu. Oleh karena itulah, masyarakat tutur di desa Sengkerang sering menyebut orang yang suka menyuruh itu dengan menggunakan perlambangan maraq datu.

\section{Flipansi (Flippancy)}

Bentuk flipansi (flippancy) yaitu bentuk ameliorasi yang menghaluskan suatu kata, tetapi makna kata yang dihasilkan di luar pernyataan. Bentuk ameliorasi ini sering digunakan oleh masyarakat ketika berkomunikasi. Kata-kata atau ujaran yang termasuk dalam kategori flipansi dianggap halus karena menggantikan kata yang dianggap tidak halus atau kasar (peyorasi) meskipun kata yang digunakan itu memiliki makna di luar pernyataan.

Orang ketika berkomunikasi terkadang tidak menghiraukan apakah kata yang dipilihnya pada saat berinteraksi itu memiliki makna yang sama atau tidak dengan maksud perkataan yang sebenarnya ingin disampaikan, selama yang disampaikan itu bisa dimengerti maka kata itu akan digunakan. Orang akan berusaha menyamarkan maksud yang sesungguhnya dengan cara menggunakan kata yang dirasa lebih halus. Berdasarkan konsep ini, ditemukan bentuk ameliorasi yang dapat dikategorikan ke dalam bentuk flipansi yaitu (a.3) Amaq molah // maling//,(a.4) Kadaq hajat //Mele nai//, (a.22) Koboq //payu dara//, (a.23) Linggis// alat kelamin pria//, (a.25)Tolang nangke // buah zakar//,(a.36)Ojok aiq//berak/kencing//,(a.37) Bejowong //pusing//,(a.38) Dateng temoe //haid//, (a.40) Kenterap timus // iri hati//, (a.42) Robek lendong semen //sudah tidak perawan// (a.43)Bukan beleq otak//suka mencuri buah-buahan di malam hari//, (a.44)son kapuk//uban//, (a.58) kapong jengku //susah//. Berikut akan dijelaskan satu persatu bentuk flipansi yang ditemukan di dalam penelitian ini.

(a.3) Amaq molah // maling// 
LINGUA, Vol. 16, No. 1, Maret 2019

p ISSN: 1979 9411; e ISSN: 2442 238X

Http://lingua.pusatbahasa.or.id; Email:presslingua@gmail.com

Center of Language and Cultural Studies, Surakarta, Indonesia

Anwar, Khairil; Syahdan \& Fadjri, Muhammad. 2019. Ameliorasi Bahasa Sasak

pada Masyarakat Tutur di Desa Sengkerang, Praya Timur: Kajian Sosiolinguistik.

Lingua (2019), 16(1): 121 136. DOI: 10.30957/lingua.v16i1.580.

Istilah amaq molah terdiri dari dua kata yaitu amaq dan molah. Kata amaq berarti ayah sedangkan kata molah berarti waktu luang atau gampang. Jadi istilah amaq molah berarti seorang ayah yang memiliki waktu luang. Dalam hal ini, ayah tersebut memiliki waktu luang dan dengan waktu yang luang itu dia sangat gampang mengambil barang orang lain. Istilah amaq molah sendiri digunakan untuk mengganti kata maling. Sebutan kata maling secara langsung kepada orang yang suka mencuri itu dirasa cukup kasar. Oleh karena itulah, disamarkan dengan menggunakan istilah amaq molah. Namun, saat ini istilah amaq molah sudah jarang digunakan oleh masyarakat seiring perkembangan zaman. Hanya orang-orang tertentu yang masih mengenal istilah amaq molah.

\section{Memodelkan Kembali (Remodeling)}

Bentuk memodelkan kembali (Remodeling), yaitu pembentuk ulang. Kata-kata yang bermakna peyorasi atau dianggap kasar diganti dengan cara memodelkan kembali kata yang dianggap kasar tersebut. Pemodelan ini berarti menghilangkan sebagian bentuk akhir dari kata yang dianggap kasar itu. Bentuk memodelkan kembali ini oleh masyarakat di desa Sengkerang sering digunakan pada kata-kata umpatan. Pengubahan ini bertujuan supaya umpatan yang diujarkan tidak terdengar kasar. Bentuk-bentuk pemodelan kembali yang ditemukan dalam penelitian ini yaitu Sundes //Sundel// //sundel// a.9 Base Basong anjing a.10 Jadek Jadah anak haram a.32 Godes Godek monyet a.33 Tainines Tele nine vagina perempuan a.34 Tolang telenines Tolang tele inaq tulang vagina perempuan/ibu a.35 Ancit ancot//senggama// a.24. Berikut akan dijelaskan satu persatu bentuk memodelkan kembali yang ditemukan di dalam penelitian ini.

\section{a.9 Sundes //sundel//}

Kata sundes merupakan bentuk pemodelan kembali dari kata umpatan sundel. Sundel sendiri berarti seorang pezina. Masyarakat di desa Sengkerang menganggap kata sundel itu sebuah kata yang sangat kasar. Orang yang dikenai kata sundel biasanya akan mudah terpancing emosinya. Oleh karena itulah, penggunaan kata sundel dipelesetkaan menjadi kata sundes. Biasanya penggunaan kata sundes dipakai untuk mengumpat oleh orang yang tidak terbiasa mengucapkan kata kasar atau tidak terbiasa mengumpat.

\section{Bentuk Sirkumlokusi (Cirkumlocutions)}

Bentuk Sirkumlokusi (Cirkumlocutions), yaitu bentuk penghalusan suatu kata dengan menggunakan beberapa kata yang lebih panjang dan bersifat tidak langsung. Sama halnya dengan desa lain, masyarakat di desa Sengkerang juga sering memperhalus ucapan dengan menggunakan beberapa kata yang lebih panjang untuk mengganti satu kata yang dianggap kasar meskipun kata yang digunakan untuk mengganti kata yang dimaksud tersebut bersifat tidak langsung. Beberapa bentuk sirkumlokusi di dalam penelitian ini yaitu (a.1) Kurang penyerioq //Rundam// 'kurang jelas penglihatan',(a.5) Jauq percek //Selaq// 'leaq', (a.7) Juan empaq basaq //Ubek// 'pelacur',(a.8) Penyakit berat //Berong// 'kusta',(a.18) Sri maseh //Solong//'rambut kepala yang tersisa di bagian 
LINGUA, Vol. 16, No. 1, Maret 2019

p ISSN: 1979 9411; e ISSN: 2442 238X

Http://lingua.pusatbahasa.or.id; Email:presslingua@gmail.com

Center of Language and Cultural Studies, Surakarta, Indonesia

Anwar, Khairil; Syahdan \& Fadjri, Muhammad. 2019. Ameliorasi Bahasa Sasak

pada Masyarakat Tutur di Desa Sengkerang, Praya Timur: Kajian Sosiolinguistik.

Lingua (2019), 16(1): 121 136. DOI: 10.30957/lingua.v16i1.580.

pinggir saja', (a.19) Kurang perengah //gedok// 'tuli,dan (a.31)' Anak kurang bulan //Anak haram//'anak haram'. Berikut akan dijelaskan satu persatu bentuk sirkumlokusi yang ada di dalam penelitian ini.

\section{(a.1) Kurang penyerioq //Rundam// 'kurang jelas penglihatan'}

Ungkapan kurangpenyerioq dikategorikan ke dalam bentuk sirkumlokusi karena digunakan untuk mengganti kata rundam. Ungkapan ini digunakan untuk memperhalus kata rundam. Kurangpenyerioq dalam bahasa Indonesia berarti tidak bisa melihat secara jelas sedangkan dalam bahasa Sasak disebut dengan istilah rundam. Kata rundam pada dasarnya bermakna suatu keadaan yang remang-remang, misalkan cahaya lampu yang tidak menyala dengan jelas. Oleh karena keadaan yang tidak jelas atau terang tersebut maka dikaitkan kepada orang yang tidak bisa melihat dengan jelas atau memiliki penglihatan yang kurang jelas. Keadaan tersebut mungkin dikarenakan usia yang sudah tua atau faktor sakit mata. Namun, menyebut rundam secara langsung kepada orang yang tidak bisa melihat secara jelas tersebut dirasa sedikit kasar sehingga biasanya masyarakat di desa Sengkerang sering menyebutnya dengan ungkapan kurang penyerioq. Kata penyerioq berasal dari kata serioq dan mendapat imbuhan pe- sehingga menjadi penyerioq. Kata serioq diambil dari bahasa alus bahasa Sasak yang berarti gitaq.

\section{Kliping (Clipping)}

Kliping (Clipping) yaitu pemotongan, membuat menjadi pendek atau singkat. Kliping digunakan oleh masyarakat tutur di desa Sengkerang untuk memperhalus katakata yang dianggap kasar atau tabu. Pemotongan itu dilakukan dengan cara menghilangkan sebagian bentuk fonem baik itu bagian depan ataupun belakang kata yang dianggap peyorasi atau bermakna kasar. Di dalam penelitian ini, ditemukan dua bentuk kliping yaitu (a.45)pep //pepeq// dan (a.63) but //jabut//. Berikut akan dijelaskan satu persatu bentuk kliping yang ditemukan.

\section{(a.63) But //jabut//}

Kata but juga termasuk dalam kategori kliping karena merupakan pemotongan dari kata jabut. Kata jabut dalam bahasa Sasak berarti bulu yang tumbuh di seluruh bagian tubuh itu agak lebat dan tidak biasanya seperti yang dialami oleh kebanyakan orang. Masyarakat di desa Sengkerang menghilangkan suku kata $j a$ dan menggunakan suku kata but untuk menyatakan kata jabut. Hal itu dilakukan agar terkesan tidak kasar.

\section{Akronim (Accronym)}

Akronim (Accronym) yaitu penyingkatan atas beberapa kata menjadi satu. Penyingkatan ini dilakukan untuk menghilangkan kesan kasar pada penyebutan yang dianggap peyorasi. Di dalam penelitian ini ditemukan dua bentuk akronim yaitu (a.17) ganteng 'Galang tengaq'dan (a.26) Termos 'Terune mosot'. Berikut akan dijelaskan satu persatu bentuk akronim yang ditemukan. 
LINGUA, Vol. 16, No. 1, Maret 2019

p ISSN: 1979 9411; e ISSN: 2442 238X

Http://lingua.pusatbahasa.or.id; Email:presslingua@gmail.com

Center of Language and Cultural Studies, Surakarta, Indonesia

Anwar, Khairil; Syahdan \& Fadjri, Muhammad. 2019. Ameliorasi Bahasa Sasak

pada Masyarakat Tutur di Desa Sengkerang, Praya Timur: Kajian Sosiolinguistik.

Lingua (2019), 16(1): 121 136. DOI: 10.30957/lingua.v16i1.580.

\section{(a.17) ganteng 'Galang tengaq'}

Ganteng termasuk dalam kategori akronim karena merupakan akronim dari kata galangtengaq. Galang tengaq yang dimaksud oleh masyarakat di desa Sengkerang yaitu rambut kepala pada bagian tengah itu tidak ada. Kata galang tengaq sendiri merupakan ameliorasi dari kata botak. Untuk menunjukkan kesan humor maka oleh masyarakat di desa Sengkerang mengakronimkan kata galang tengaq menjadi ganteng. Kadang orang yang mendengar penyebutan ini akan tersenyum bahkan kalau orang yang tidak paham maksudnya akan menanyakan arti dari kata ganteng tersebut. Sesungguhnya kata ganteng berarti seorang pria yang gagah atau tampan.

\section{Singkatan (Abbreviations)}

Penggunaan ameliorasi bahasa Sasak di desa Sengkerang juga dilakukan dengan cara mengganti kata yang bermakna kasar itu dengan singkatan. Singkatan (Abbreviations) yaitu singkatan kata-kata menjadi beberapa huruf. Kata-kata yang dianggap kasar oleh masyarakat di desa Sengkerang disingkat agar terkesan tidak kasar tetapi malah akan terkesan keren. Di dalam penelitian ini ditemukan dua bentuk singkatan yaitu (a.16) Jb 'Jaber beweh' dan (a.30) ksp 'Kalah siq pepeq'. Berikut akan dijelaskan makna dari bentuk singkatan yang ada dalam penelitian ini.

\section{(a.16) Jb 'Jaber beweh'}

Singkatan $j b$ termasuk dalam kategori singkatan karena merupakan bentuksingkatandari jaber beweh. Jaberbeweh dalam bahasa Indonesia berarti bentuk mulut yang besar. Bentuk singkatan $j b$ ini oleh masyarakat di desa Sengkerang dianggap memiliki kesan tidak kasar meskipun maknanya tetap mengacu pada kesan yang kurang baik. Singkatan $j b$ ini biasanya digunakan untuk mengikuti nama seseorang yang dianggap memiliki bentuk mulut yang besar.

\section{(a.30) ksp 'Kalah siq pepeq'}

Bentuk singkatan ksp termasuk kategori singkatan karena digunakan untuk memperhalus kata kalah siq pepeq. Bentuk singkatan ini banyak digunakan oleh kalangan remaja. Ungkapan kalah siq pepeq berasal dari tiga kata yaitu kalah //kalah// + siq //oleh// + pepeq //vagina//. Ksp pada dasarnya adalah sebuah singkatan yang terdapat di perguruan tinggi. Di perguruan tinggi singkatan $k s p$ memiliki kepanjangan yaitu Kuliah Semester Pendek. Singkatan ini diadopsi oleh remaja untuk menyebut seorang cowok yang kalah oleh perempuan. Maksud kalah di sini yaitu setiap apa yang diinginkan oleh pacarnya dia selalu menurutinya dan sedikitpun tidak berani membantah. Oleh karena itulah, seorang cowok yang selalu mengikuti kemauan pacarnya dianggap $k s p$. 
LINGUA, Vol. 16, No. 1, Maret 2019

p ISSN: 1979 9411; e ISSN: 2442 238X

Http://lingua.pusatbahasa.or.id; Email:presslingua@gmail.com

Center of Language and Cultural Studies, Surakarta, Indonesia

Anwar, Khairil; Syahdan \& Fadjri, Muhammad. 2019. Ameliorasi Bahasa Sasak

pada Masyarakat Tutur di Desa Sengkerang, Praya Timur: Kajian Sosiolinguistik.

Lingua (2019), 16(1): 121 136. DOI: 10.30957/lingua.v16i1.580.

\section{Hipernim (general for spesific)}

Hipernim (general for spesific), yaitu kata yang umum menjadi kata yang khusus. Bentuk ameliorasi ini banyak digunakan oleh masyarakat di desa Sengkerang untuk menyatakan sikap penghormatan kepada orang lain. Penggunaan bentuk ini juga bertujuan untuk mengaburkan makna kata yang sesungguhnya. Terkadang orang akan dibuat sedikit bingung dengan penggunaan ameliorasi ini karena sifatnya yang umum. Butuh pertanyaan lanjutan untuk memperjelas maksud dari kata yang digunakan untuk mengaburkan makna ini. Beberapa kata yang termasuk dalam kategori hipernim (general for spesific) yang berhasil ditemukan di dalam penelitian ini yaitu (a.29) beleq //gendut//'gemuk',(a.41) manjaq //Kodeq susu//'Payudara kecil', (a.37) bejowong //kepineng//"pusing', dan(a.59) tindoq bareng //ngancot//'bersenggama'. berikut akan dijelaskan satu persatu bentuk hipernim yang berhasil ditemukan.

\section{(a.29) beleq //gendut//'gemuk'}

Kata beleq //besar// termasuk dalam kategori hipernim (general for spesific) karena merupakan bentuk yang sangat umum. Kata beleq digunakan untuk mengganti kata gendut 'gemuk'. Kata beleq pada dasarnya memiliki makna yang sangat luas. Kalau menyebut kata beleq saja biasanya orang akan kurang paham maksud dari penutur. Sedangkan kalau orang menyebut kata gendut maka pikiran akan tertuju pada bentuk tubuh yang besar. Namun, apabila seseorang menyebut kata gendut kepada temannya kemungkinan temannya itu atau orang yang dimaksud itu akan merasa tersinggung. Oleh karena itulah, untuk menyamarkan maksud dari penutur untuk menyatakan gendut maka digunakanlah kata beleq. Masyarakat di desa Sengekerang merasa penyebutan kata beleq untuk mengganti kata gendut dianggap lebih sopan dan memiliki nilai rasa yang lebih tinggi.

\section{Hiponim (part for whole euphemisms)}

Hiponim (part for whole euphemisms) merupakan bentuk kebalikan dari hipernim. hipernim berarti penggunaan kata yang umum menjadi kata yang khusus sedangkan hiponim merupakan bentuk kata yang khusus menjadi kata yang umum. Bentuk hiponim ini sering pula digunakan oleh masyarakat di desa Sengkerang untuk menyamarkan maksud sesungguhnya supaya apa yang hendak disampaikan terkesan memiliki nilai rasa yang lebih tinggi. Berdasarkan konsep ini, ditemukan beberapa bentuk hiponim di dalam penelitian ini. Beberapa bentuk tersebut yaitu (a.46) beraiq erung //seleme//'filek', (a.47) pereq beweh //guam//'sariawan',(a.48) peres mate //ngantok//'ngantuk',(a.49)panas tian //lapah//'lapar', dan(a.50) leteng tian //sakit tian//sakit perut'. Berikut akan dipaparkan satu persatu bentuk hiponim yang ditemukan dalam penelitian ini.

\section{(a.46) beraiq erung //seleme//'pilek'}

Ungkapan beraiq erung 'hidung berair' merupakan sebuah ekspresi yang termasuk dalam kategori hiponim. Ekspresi ini oleh masyarakat di desa Sengkerang 
LINGUA, Vol. 16, No. 1, Maret 2019

p ISSN: 1979 9411; e ISSN: 2442 238X

Http://lingua.pusatbahasa.or.id; Email:presslingua@gmail.com

Center of Language and Cultural Studies, Surakarta, Indonesia

Anwar, Khairil; Syahdan \& Fadjri, Muhammad. 2019. Ameliorasi Bahasa Sasak

pada Masyarakat Tutur di Desa Sengkerang, Praya Timur: Kajian Sosiolinguistik.

Lingua (2019), 16(1): 121 136. DOI: 10.30957/lingua.v16i1.580.

digunakan untuk menyamarkan kata seleme 'pilek'. Terkadang orang tidak mau langsung menganggap dirinya mengalami sakit. Untuk menyatakan sakitnya itu, kadang untuk menyebutnya digunakan gejala apa saja yang menandakan penyakit itu. Dalam hal ini, digunakan kata beraiq erung untuk menyatakan sakit seleme.

\section{Hiperbola (Hyperbole)}

Hiperbola (Hyperbole) yaitu ungkapan yang melebih-lebihkan. Hiperbola biasanya digunakan untuk memperoleh efek tertentu. Selain untuk mendapatkan efek tertentu, masyarakat di desa Sengkerang sering menggunakan kata-kata yang mengandung makna hiperbola untuk mengganti kata-kata yang dianggap tidak sopan atau kurang memiliki nilai rasa agar terdengar lebih sopan. Di dalam penelitian ini, ditemukan beberapa bentuk hiperbola untuk mengganti kata-kata tertentu. Beberapa bentuk hiperbola tersebut yaitu (a.60)wahng ntaq leq surge //sudah di syurga// 'sudah mati', (a.61) wahng ntaq ngimpi //sudah bermimpi// 'sudah tidur', dan (a.62). wah ntaq dateng mekah embokng //sudah sampai mekah nafasnya// 'tidur yang sangat pulas'. Berikut akan dijelaskan satu persatu bentuk hiperbola tersebut.

\section{(a.60) wahng ntaq leq surge //sudah di syurga// 'sudah mati'}

Data pada a.60 termasuk dalam kategori hiperbola karena merupakan sebuah ungkapan untuk menyatakan orang yang sudah mati tetapi menggunakan kalimat wahng ntaq leq surge //dia sudah di surga// agar muncul kesan menghormati orang yang sudah meninggal. Orang yang dimaksud di sini biasanya semasa masih hidup memiliki sifat yang baik. Ungkapan wahng ntaqleq surge //dia sudah di surga// digunakan untuk mengganti kata uwah mate //sudah mati//. Kata uwah mate apabila diucapkan untuk orang baik yang sudah meninggal menurut masyarakat di desa Sengkerang bahkan masyarakat di luar desa Sengkerang juga menganggap pemakaian kata uwah mate itu kurang sopan bahkan dianggap kasar.

\section{Jargon}

Bentuk ameliorasi yang terakhir yang ditemukan di dalam penelitian ini adalah bentuk jargon. Bentuk jargon yaitu kata yang memiliki makna yang sama tetapi berbeda bentuk. Masyarakat di desa Sengkerang sering menggunakan bentuk jargon untuk memperhalus kata yang dianggap kasar atau memiliki nilai rasa yang lebih rendah. Beberapa bentuk jargon untuk memperhalus tuturan yang berhasil ditemukan di dalam penelitian ini yaitu (a.2) ninggal //mate//'meninggal dunia', (a.6) ajaq //lekak//'bohong', (a.15)belo //lenjang//'badan yang sangat tinggi', (a.13) Macel //Lejah//'nakal'. Berikut akan dijelaskan satu persatu bentuk jargon yang masih hidup di tengah masyarakat yang berhasil ditemukan.

(a.2) ninggal //mate// 'meninggal dunia' 
LINGUA, Vol. 16, No. 1, Maret 2019

p ISSN: 1979 9411; e ISSN: 2442 238X

Http://lingua.pusatbahasa.or.id; Email:presslingua@gmail.com

Center of Language and Cultural Studies, Surakarta, Indonesia

Anwar, Khairil; Syahdan \& Fadjri, Muhammad. 2019. Ameliorasi Bahasa Sasak

pada Masyarakat Tutur di Desa Sengkerang, Praya Timur: Kajian Sosiolinguistik.

Lingua (2019), 16(1): 121 136. DOI: 10.30957/lingua.v16i1.580.

Kata ninggal memiliki makna yang sama dengan kata mate yakni sama-sama bermakna mati.Oleh karena itulah, kata ninggal termasuk dalam kategori jargon. Kata ninggal digunakan oleh masyarakat di desa Sengkerang untuk menggantikan kata mate dengan maksud agar terkesan lebih positif dan memiliki nilai rasa yang lebih tinggi. Biasanya penggunaan kata mate dipergunakan untuk orang yang kurang dihormati. Sedangkan kata ninggal biasanya digunakan untuk orang yang lebih dihormati.

\section{SIMPULAN}

Bentuk ameliorasi yang sering digunakan dalam peristiwa tutur pada masyarakat tutur di desa Sengkerang kecamatan Praya Timur bervariasi. Tidak semua bentuk ameliorasi seperti yang diungkapkan oleh Allan Keith dan Keith Burridge ditemukan pada data tuturan di dalam penelitian ini. Bentuk ameliorasi yang ditemukan sebanyak sebelas bentuk. Bentuk-bentuk ameliorasi tersebut adalah 1) bentuk figuratif, 2) flipansi, 3) memodelkan kembali, 4) sirkumlokusi, 5) kliping, 6) akronim, 7) singkatan, 8) jargon, 9) hipernim, 10) hiponim, dan 11) hiperbola. Selanjutnya, makna bentuk ameliorasi yang dituturkan tersebut didasarkan pada konteks tuturan tersebut diujarkan. Tuturan yang diujarkan oleh seseorang (penutur) tidak semata-mata mengatakan sesuatu dengan mengucapkan tuturan itu, namun penutur juga menginginkan sesuatu atau penutur memiliki maksud atau tujuan tertentu.

Adapun faktor yang menyebabkan penggunaan ameliorasi yaitufaktor pertimbangan kemanusiaan, psikologis, sosiologis, religius, dan faktor humor.Faktor inilah yang mempengaruhi penggunaan suatu bahasa. Begitu pula dengan penggunaan ameliorasi.

Masyarakat tutur di desa Sengkerang Kecamatan Praya Timur menggunakan ameliorasi sebagai wujud cerminan kebudayaan yang mereka miliki. Rasa saling menghormati antarsesama menjadi pijakan ketika hendak berinteraksi. Dengan adanya budaya saling mengormati ini diharapkan dapat memicu kedamaian dan ketentraman di dalam kehidupan bermasyarakat.

\section{DAFTAR PUSTAKA}

Aminuddin. 2003. Semantik Pendekatan Studi Tentang Makna. Bandung: Sinar Baru Algensindo.

Arimi, Sailal. 2003. Ihwal Metode Penelitian Sosiolinguistik. Universitas Gadjah Mada: Jurusan Sastra Indonesia Fakultas Ilmu Budaya.

Burker, Chris. 2004. CulturalStudies: Teori \& Praktik. Yogyakarta: Kreasi Wacana.

Chaer, Abdul. 2012. LinguistikUmum (Edisirevisi). Jakarta: Rineka Cipta.

....... 2009. Pengantar Semantik Bahasa Indonesia.Jakarta:Rineka Cipta.

....... 2007. LinguistikUmum (Edisirevisi). Jakarta: Rineka cipta.

........ 2003. Linguistik Umum. Jakarta: Rineka Cipta.

Chaer, Abdul dan Leonie Agustina. 2010. Sosiolinguistik: Perkenalan Awal (Edisi Revisi). Jakarta: PT Rineka Cipta.

Christope Iwong, Henry. 2011. Perubahan Makna dalam Wacana Mob (Humor) Bahasa Melayu Papua (sebuah kajian semantik)(Tesis). Universitas Negeri Malang. 
LINGUA, Vol. 16, No. 1, Maret 2019

p ISSN: 1979 9411; e ISSN: 2442 238X

Http://lingua.pusatbahasa.or.id; Email: presslingua@gmail.com

Center of Language and Cultural Studies, Surakarta, Indonesia

Anwar, Khairil; Syahdan \& Fadjri, Muhammad. 2019. Ameliorasi Bahasa Sasak

pada Masyarakat Tutur di Desa Sengkerang, Praya Timur: Kajian Sosiolinguistik.

Lingua (2019), 16(1): 121 136. DOI: 10.30957/lingua.v16i1.580.

Cummings, Loise 2007. Pragmatik. Yogyakarta: Pustaka Pelajar.

Departemen Pendidikan Nasional. 2008. Kamus Besar Bahasa Indonesia. Jakarta: Gramedia Pustaka Utama.

Djajasudarma, T. Fatimah. 1999. Semantik 2 Pemahaman Ilmu Makna. Bandung: PT Refika Aditama.

2009. Semantik 2. Bandung: Refika Aditama.

2010. MetodeLinguistik: Ancangan Metode Penelitian dan Kajian. Bandung:

Refika Aditama.

Djokokencono. 1978. "Beberapa Masalah Lafal Standar" Pengajaran Bahasa dan Sastra. Th. V, No. 5:16-23

Elisa Nurul Laili. 2012. Eufemisme Dan Disfemisme Pada Wacana Lingkungan:

Sebuah Kajian Ekolinguistik Kritis Dalam Media Massa Di Indonesia.

Yoygayakarta. Universitas Gajah Mada.

Hasyim, Muhammad. 2012. Eufemisme Al-Qur'an: Telaah Sosiolinguistik-Semantik Atas Bahasa Tabu (tesis). UINMalang.

Hidayat, Asep Ahmad.2009.FILSAFAT BAHASA: Mengungkap Hakikat Bahasa, Makna dan Tanda. Bandung: Remaja Rosdakarya.

http://ferdinan01.blogspot.com/2009/02/pengertian-sosiolinguistik-ii.html// diakses

tanggal 20 Januari 2017. 19.05 wita.

http://santripk-newden.blogspot.com/2011/05/sosiolinguistik.html/ tanggal 20 Januari

2017. 19.20 wita

Ibrahim Syukur. 1995. SOSIOLINGUISTIK:Sajian Tujuan, Pendekatan, Dan ProblemProblemnya. Surabaya: Usaha Penerbit.

Jendra, I Wayan, 1991. Dasar-dasar Sosiolinguistik. Denpasar: Ikayana.

Jendra, I Wayan, 2007. Sosiolinguistik; Teori dan Penerapannya. Surabaya: Paramita.

Koentjaraningrat. 2009. Pengantar Ilmu Antropologi. Jakarta: Rineka Cipta.

Kridalaksana, Harimurti. 1982. Kamus Linguistik. Jakarta. Rineka Cipta.

Mahsun. 2007. Metode Penelitian Bahasa: Tahapan Strategi, Metode, dan Tekniknya (EdisiRevisi). Jakarta: PT Raja Grafindo Persada.

Mahyuni, dkk. 1992. "Unggah-ungguh Bahasa Sasak (LaporanPenelitian)". Mataram: FKIP UNRAM.

Nababan, P.W.J. 1984. Sosiolinguistik. Jakarta: Gramedia.

Pateda, Mansoer.2001. Semantik Leksikal. Jakarta: Rineka Cipta.

Prasetyo, Lery. 2015. Tabu Bahasa Dan Eufemisme Dalam Bahasa Inggris (Tesis) Yogyakarta: Universitas Gadjah Mada.

Prihartini, Ariyani. 2006. "Pengaruh Makna Tingkat Tutur Dalam Bahasa Sasak dan Hubungannya Dengan Nada Pilihan Bahasa Masyarakat Desa Sakra Kabupaten Lombok Timur". (Skripsi). Mataram: UNRAM.

Rahardi, Kunjana. 2001. Sosiolinguistik, Kode dan Alih Kode. Yogyakarta: Pustaka Pelajar.

Ramlan, M. 1986. Ilmu Bahasa Indonesia Sintaksis. Yogyakarta: C.V. Karyono.

Rohmadi, Muhammad, dkk. 2009. Morfologi Telaah Morfem dan Kata. Surakarta: Yuma Pustaka. 
LINGUA, Vol. 16, No. 1, Maret 2019

p ISSN: 1979 9411; e ISSN: 2442 238X

Http://lingua.pusatbahasa.or.id; Email:presslingua@gmail.com

Center of Language and Cultural Studies, Surakarta, Indonesia

Anwar, Khairil; Syahdan \& Fadjri, Muhammad. 2019. Ameliorasi Bahasa Sasak

pada Masyarakat Tutur di Desa Sengkerang, Praya Timur: Kajian Sosiolinguistik. Lingua (2019), 16(1): 121 136. DOI: 10.30957/lingua.v16i1.580.

Sari, Ayu Anita Mustika. 2013. "Perubahan Makna dalam Novel Moga Bunda Disayang Allah Karya Tere-Liye". (Skripsi). Surakarta: Universitas Muhammadiyah Surakarta.

Sibarani, Robert. 2004. Antropolinguistik. Medan: Penerbit Poda.

Sumarsono dan Paina Partana. 2007. Sosiolinguistik. Yogyakarta: Sabda.

Sumarsono. 2014. Sosiolinguistik. Yogyakarta: Pustaka Pelajar.

Suwandi, Sarwiji. 2008. Semantik Pengantar Kajian Makna. Yogyakarta: KLEIN Press.

Thomas, Linda dan Shan Wareing. 2007. Bahasa, Masyarakat dan Kekuasaan. Yogyakarta: Pustaka Pelajar.

Ullman, Stephen. 2009. Pengantar Semantik.Yogyakarta: Pustaka Pelajar. 
LINGUA, Vol. 16, No. 1, Maret 2019

p ISSN: 1979 9411; e ISSN: 2442 238X

Http://lingua.pusatbahasa.or.id; Email:presslingua@gmail.com

Center of Language and Cultural Studies, Surakarta, Indonesia

Anwar, Khairil; Syahdan \& Fadjri, Muhammad. 2019. Ameliorasi Bahasa Sasak

pada Masyarakat Tutur di Desa Sengkerang, Praya Timur: Kajian Sosiolinguistik.

Lingua (2019), 16(1): 121 136. DOI: 10.30957/lingua.v16i1.580. 